\title{
The efficiency analysis of the SH-25A ball drum mill when grinding industrial products of fossil fuels
}

\author{
Saule Kamarova ${ }^{1}$, Saule Abildinova ${ }^{1}$, Angel Terziev ${ }^{2, *}$, and Aliya Elemanova ${ }^{1}$ \\ ${ }^{1}$ Department of Industrial Heat Technology, Almaty University of Power Engineering and \\ Telecommunications, Almaty, Kazakhstan \\ ${ }^{2}$ Department of Power Engineering and Power Machines, Technical University of Sofia, 8 Kliment \\ Ohridski blvd., 1000 Sofia, Bulgaria
}

\begin{abstract}
The working characteristics of a laboratory ball drum mill during grinding of Karaganda coal products were studied in order to apply the results obtained to industrial installations. The performed analysis shows that the most complicated and energy-intensive stage of preparation of coal dust is the grinding of fuel. The operational characteristics of the mill productivity, consumed electric power and specific energy consumption in terms of the relative rotational speed of the drum as well as the optimal values of the relative velocity determining the qualitative grinding of the fuel have been determined. The performance of the processed drum mill reaches its maximum at a relative speed of rotation of the drum 0.71 ensuring a waterfall mode of grinding of fuel related to the high-speed mode of a coal-grinding mill. The estimated specific energy consumption for fuel grinding varies in the range from $0.11 \mathrm{kWh} / \mathrm{kg}$ up to $0.23 \mathrm{kWh} / \mathrm{kg}$ at fuel milling coefficient of $\mathrm{Kl}=1.2$.
\end{abstract}

\section{Introduction}

The most complicated and energy-intensive stage of preparation of coal dust is the grinding of fuel. For reliable, economical and safe operation of the dust preparation equipment, it is necessary to focus to the entire system for preparation and grinding of fuel at thermal power plants. The process of fuel grinding must be implemented in such way to ensure: uniform fuel supply to all boiler burners; the required amount of coal fuel, grounded to a required fineness and dried to the required humidity [1].

The dust preparation system equipped with ball drum mills (BDM) is widely used in many thermal power plants (TPP) for grinding different types of solid fuel. The main disadvantage of the BDM is the significant electricity consumption, which at the TPP level is about a quarter of the total electricity consumption for own needs. Hence the total electricity production decreases. The stated above shows that the solid fuel requires the most complicated and expensive preparation before combustion. Therefore, methods for

* Corresponding author: aterziev@,tu-sofia.bg 
improving the technology for coal preparation and further combustion are currently very relevant [2].

The purpose of the study is to improve the efficiency of the BDM because of their widespread use in many industries.

\section{General information}

The focus of the study is the TPP-2 station which is the structural subdivision of OJSC ArcelorMittalTemirtau (AMT) of the city of Temirtau, Karaganda region. An individual closed pulverization system with an intermediate bunker equipped with a ball drum mill currently operates at TPP-2. The installation includes two ball drum mills SH-25A with a total capacity of $34.3 \mathrm{t} / \mathrm{h}$ when grinding industrial Karaganda coals [3].

At present, the efficiency of the installed in TPP-2 of OJSC AMT equipment is below the average level for such type of systems. The degree of deterioration of the main equipment is more than $60 \%$ while about $50 \%$ of electrical grid failures and emergencies often occur during operation. Analysis of the dust preparation system for TPP-2 shows: increased specific energy consumption for dust preparation from $25 \mathrm{kWh}$ up to $35 \mathrm{kWh}$ per 1 ton of dust produced; significant wear of the metal (ball units) during operation (about $400 \mathrm{~g}$ of metal is spent when preparing 1 ton of dust); degraded grinding properties and insufficient drying capacity of the mill; technological processes of grinding are poorly automated [4].

Based on the above, improvements of the pulverizing system of BDM at TPP-2 must be searched in the optimization of the operating modes of the mills and the automation of the grinding process. Also determining the optimum speed of the mill during grinding is crucial for increasing the mill efficiency [5].

\section{Experimental study}

For the purpose of the study an experimental equipment of BDM grinding industrial products was built. The results obtained should be successfully used to improve the efficiency of the industrial facilities. The test bench consists of a laboratory non-ventilated BDM equipped with a frequency converter and energy meter. The block-scheme of the laboratory equipment is presented in Fig.1.

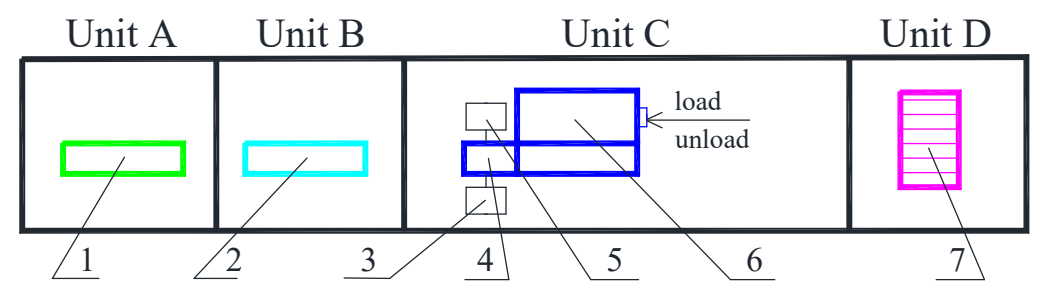

1-drying chamber, 2-scale CAS MWP-600 type, 3-electricity meter (multimeter) IMS F-1 type, 4electric drive, 5-pulse-frequency control point adjustment unit (frequency transformer vector FTV1$\mathrm{HH}), 6$ - porcelain ball drum grinder (active zone: internal diameter - $210 \mathrm{~mm}$, depth - $190 \mathrm{~mm}$ ), 7 shaker screen AS-200 type.

Unit A - place for measuring humidity and particle size distribution at the inlet; Unit B - place for measuring of weight coal characteristics at the inlet and outlet; Unit C - input coal grinding unit; Unit $\mathrm{D}$ is the Screen analysis of the processed dust.

Fig. 1. Block-scheme of the process of grinding industrial products 
The experimental study shows that the number of revolutions of the mill is determined by the diameter of the drum. At slower speed of the mill, the angle of lifting of the balls is low hence the performance is low. At high speeds of rotation of the mill, centrifugal forces exceed the gravitational forces of the balls. At a critical speed, the centrifugal force acting on the balls will catch up with their weight, and the balls, pressed by the centrifugal force to the wall of the drum will rotate with the drum. The minimum peripheral speed of the inner surface, at which the critical number of revolutions of the BDM occurs, is determined by the Eq. $1[6]$ :

$$
\mathrm{n}_{\mathrm{cr}}=\frac{42.4}{D^{1 / 2}}, \mathrm{rpm}
$$

where $\mathrm{n}_{\mathrm{cr}}$ - range of speeds, $\min ^{-1} ; \mathrm{D}$ - diameter of a BDM, m

The working number of revolutions of BDM is about $75 \%$ of the critical number of revolutions:

$$
\mathrm{n}=\frac{32}{D^{1 / 2}}, \mathrm{rpm}
$$

Estimated working speed of the mill:

-The critical and working number of revolutions of a laboratory mill are: $92 \mathrm{rpm}$; $71 \mathrm{rpm}$.

-The degree of filling the drum with grinding balls also affects the performance of the mill and the efficiency of grinding. The degree of filling of the drum with balls is according the methodology [7]:

$$
\phi_{\mathrm{b}}=\frac{\mathrm{G}_{\mathrm{b}}}{\gamma_{\mathrm{bd}} \cdot \mathrm{V}_{\mathrm{i}}},
$$

where $G_{b}$ is the mass of balls loading the mill, which is function of filling degree of mill with balls and their diameter, $\mathrm{kg} ; \gamma_{\mathrm{bd}}$ - bulk density of balls, $\mathrm{kg} / \mathrm{m}^{3} ; \mathrm{V}_{\mathrm{i}}-$ internal volume of the drum, $\mathrm{m}^{3}$.

The degree of filling of the drum with balls is $\phi_{\mathrm{b}}=0.2$.

Study of the efficiency of the ball drum mills SH-25A was performed with sample of Karaganda industrial coals. The Karaganda coals was collected from the boiler room of TPP-2 of AMT OJSC. The composition of the fuel is as follow: $\mathrm{Sp}=0.8 \%$; $\mathrm{Cp}=53.7 \%$; $\mathrm{H}^{\mathrm{p}}$ $=3.3 \% ; \mathrm{Np}=0.8 \% ; \mathrm{O}^{\mathrm{p}}=4.8 . \mathrm{Wp}=9.0 \% ; \mathrm{A}^{\mathrm{p}}=27.6 \%$. summarized information for the thermal characteristics of the Karaganda colas are presented in Table 1.

Table 1. Thermal properties of the proposed fuel.

\begin{tabular}{|c|c|c|c|c|c|c|}
\hline \multirow{2}{*}{ Coal brand } & \multirow{2}{*}{$\begin{array}{c}\text { Heat of } \\
\text { combustion } \\
\end{array}$} & \multirow{2}{*}{$\begin{array}{c}\text { Content of } \\
\text { volatiles }\end{array}$} & \begin{tabular}{c} 
Grinding \\
coefficient \\
\cline { 5 - 7 }
\end{tabular} & \multicolumn{3}{|c|}{ Ash melting temperature } \\
\cline { 5 - 7 } & $\mathrm{V}^{\mathrm{v}}, \%$ & $\mathrm{~kg}$ & $K_{1}, \%$ & $\begin{array}{c}\text { Initiating } \\
\text { deformation }\end{array}$ & Softening & $\begin{array}{c}\text { Liquid- } \\
\text { fusible state }\end{array}$ \\
\hline $\begin{array}{c}\text { Karaganda } \\
\text { coal }\end{array}$ & 20.222 & 28 & 1.2 & 1400 & 1450 & 1470 \\
\hline
\end{tabular}

The study of the grinding process includes the following steps: drying the coal in a convective dryer; weighing the grinding amount of coal; direct grinding to determine the energy performance of the mill; determining the fractional composition of the resulting coal 
dust via sieve analysis. Sieving analysis of coal dust is performed with vibrating screens with various diameters $1000,500,200,90,71 \mu \mathrm{m}$

The experimental equipment is presented in Figure 2.

To remove extra moisture, the test sample of coal was pre-dried in a convective dryer to a moisture content of $W^{c}=4 \%$. Analytical moisture $\left(W^{c}\right)$ is determined for a laboratory sample of coal where particle size is from 0 up to $3 \mathrm{~mm}$ with a mass of $500 \mathrm{~g}$.

The laboratory ball drum mill (Fig. 2) was filled with metal balls $28 \mathrm{~mm}$ in diameter (with a total mass of $5 \mathrm{~kg}$ ) and $15 \mathrm{~mm}$ in diameter (with a total mass of $2 \mathrm{~kg}$ ).

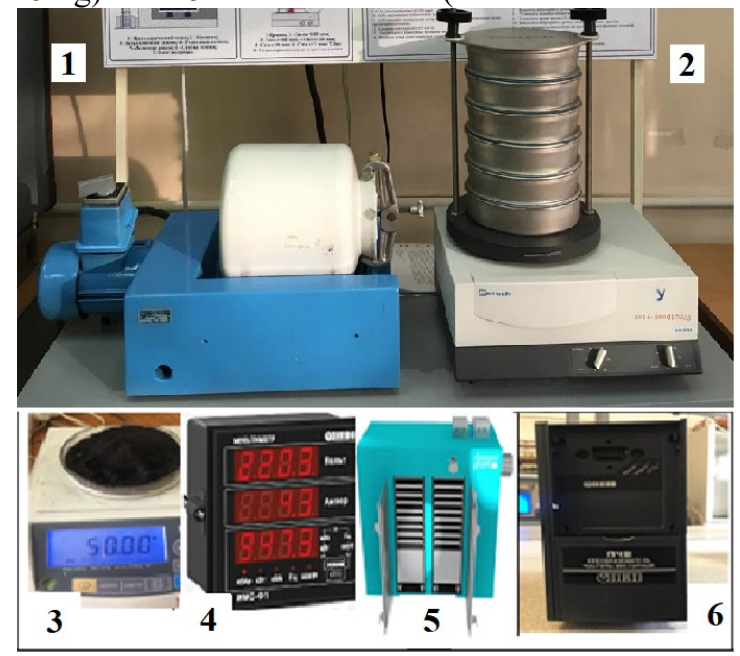

1-ball drum mill; 2 - Retsch AS200 vibrating screen; 3- electronic scales CAS MWP-600; 4- IC F-1 multimeter; 5- drying chamber; 6- vector frequency converter frequency converter B1-XX.

Fig. 2. Overview of the grinding and measuring equipment using during the experimental study

The performance of an industrial BDM generally depends on the properties of the coal being milled, more precisely on the strength, grinding ability, size of pieces entering the mill (up to $50 \mathrm{~mm}$ ), moisture content of materials (up to $0.5 \%$ ), comminution degree, degree of filling BDM with coals and balls. Experimentally, the performance of mill can be expressed with the following expression [7]:

$$
\mathrm{B}=\mathrm{k} \cdot \mathrm{D}^{2.4} \cdot \mathrm{n}^{0.8} \cdot \phi^{0.6} \cdot \mathrm{L}, \mathrm{kg} / \mathrm{h}
$$

where $\mathrm{B}$ - is the mill productivity, $\mathrm{kg} / \mathrm{h}$; $\mathrm{k}$ is the correction factor for the fineness of the grinding (with a residue on a sieve of $90 \mu \mathrm{m}$ from 2 up to $20 \%$, the value of $\mathrm{k}$ varies from 0.5 to 1.5 , respectively), here it is accepted $\mathrm{k}=1 ; \mathrm{D}$ - internal diameter, $\mathrm{m}$; $\mathrm{L}$ - is the length of the mill, $\mathrm{m} ; \phi$ - filling factor of mill; $\mathrm{n}$ - mill rotation frequency, $\mathrm{rpm}$.

The consumed electrical power of the laboratory mill depends on the working speed of the engine:

$$
\mathrm{N}_{\mathrm{ep}}=0.214 \cdot \mathrm{D}^{2} \cdot \mathrm{n}, \mathrm{kWt}
$$

The mill efficiency will be either specified as specific performance or specific consumption of electricity for grinding [1]: 


$$
\mathrm{E}=\frac{\mathrm{N}_{\mathrm{ep}}}{\mathrm{B}}, \mathrm{kWh} / \mathrm{kg}
$$

Table 2 presents the results from the experimental study when grinding the Karaganda coals in terms of relative rotation speed.

Table 2. The performance characteristics of experimental BDM

\begin{tabular}{|c|c|c|c|}
\hline $\begin{array}{c}\text { Relative } \\
\text { rotational speed }\end{array}$ & Power, $\mathrm{kWt}$ & $\begin{array}{c}\text { Performance, } \\
\mathrm{kg} / \mathrm{h}\end{array}$ & $\begin{array}{c}\text { Specific electricity } \\
\text { consumption, } \mathrm{kWh} / \mathrm{kg}\end{array}$ \\
\hline 0.59 & 0.32 & 2.86 & 0.11 \\
\hline 0.65 & 0.55 & 2.89 & 0.19 \\
\hline 0.7 & 0.59 & 2.92 & 0.20 \\
\hline 0.71 & 0.65 & 3.0 & 0.22 \\
\hline 0.81 & 0.67 & 2.93 & 0.23 \\
\hline 0.86 & 0.61 & 2.87 & 0.21 \\
\hline 0.92 & 0.58 & 2.84 & 0.20 \\
\hline 0.97 & 0.5 & 2.78 & 0.18 \\
\hline 1.03 & 0.4 & 2.75 & 0.15 \\
\hline
\end{tabular}

The efficiency of the mechanical mode of operation of a ball drum mill is determined by two main parameters [8]:

-relative speed of rotation of the drum $\psi=\frac{n}{n_{c r}}$;

-coefficient of relative filling of the mill with grinding balls $\phi=\frac{\mathrm{V}_{\mathrm{B}}}{\mathrm{V}}$.

On Figure 3 are presented the results of grinding the test coal in a laboratory nonventilated $B D M$ with $D=210 \mathrm{~mm}$, relative length $\frac{L}{D}=0.9$ and the wave-like form of cover at various mill revolutions of the mill and the degree of filling with balls $\varphi_{b}=0.2$ and the fineness of dust $R_{90}=22 \%$.

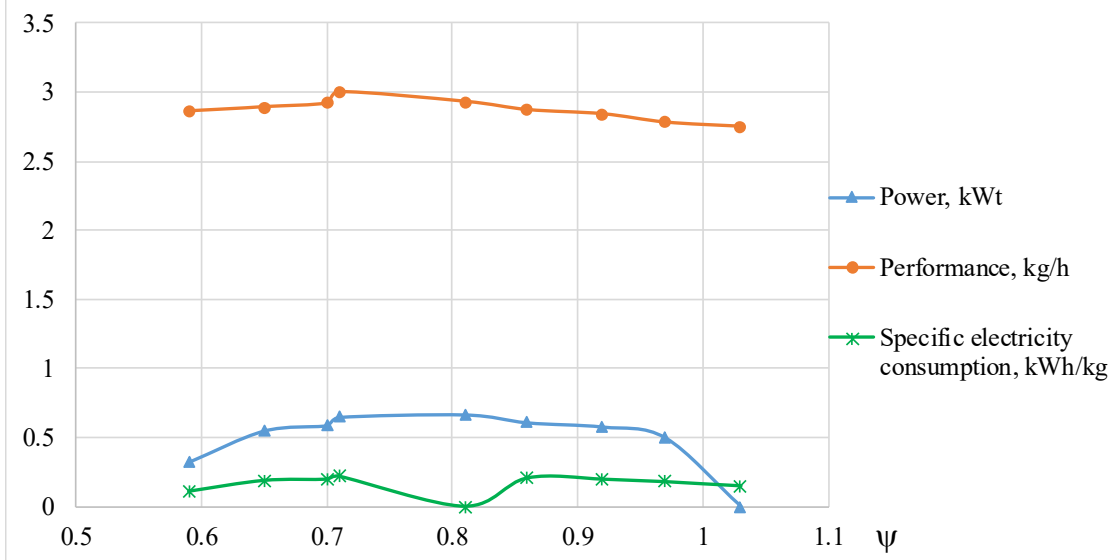

Fig. 3. Performance, power and specific power consumption curves at different operational modes of mill drum

The change in performance of the mill in terms of relative rotational speed of the drum is uneven, where the maximum change is at value $\psi=0.71$. Further increase in the relative speed causes grinding bodies (balls) to fall in the center of the drum because of a decreased separation angle. In this case the grinding bodies do not reach the fuel but only bare surface, i.e. fuel grinding is not in place. The potential energy of the falling balls is not spent efficiently for a heating, as metal wear and losses in mechanical transmission occurs. 
Power and specific energy consumption with an increase in the relative speed of drum rotation in terms of performance slightly changes.

The following motion modes of the grinding bodies inside the rotating drum can be distinguished:

-cascade, with rolling grinding bodies without flight;

-mixed, partly with rolling milling bodies and partly with flight;

-waterfall, with the predominant flight of grinding media, including subcritical, when approaching centrifugation or with centrifugation of the outer grinding layers;

-supercritical or "flywheel", with centrifuging of the entire volume of grinding bodies.

High-quality grinding of fuel corresponds to the waterfall regime [8]. The angle of separation of the grinding body is shown along the section of the drum in Figure 4. With a faster rotation of the drum, the balls under the influence of centrifugal force are pressed against the wall, rise and then fall down with a parabolic trajectory (Figure 4a).

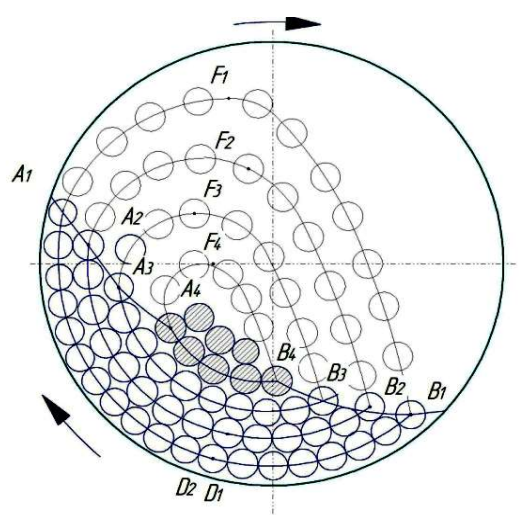

a)

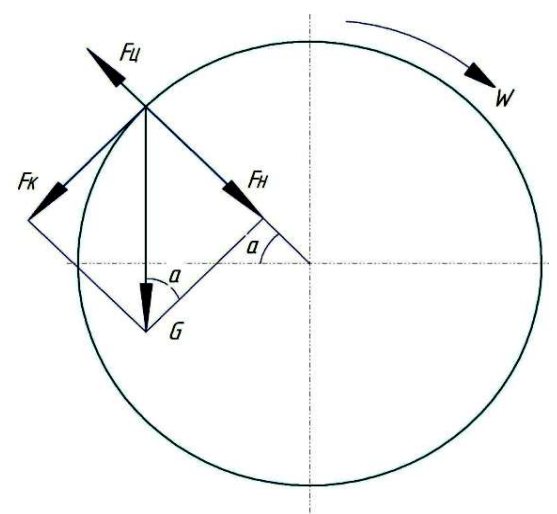

b)

Fig. 4. Motion of grinding bodies inside rotating drum, corresponding to high-quality frame of fuel and its characteristics: a) movement of the balls inside the BDM; b) Applied force scheme.

The relative speed of rotation of the drum has a maximum at a value of $\varphi=0.71$ ensuring the transition of most layers of grinding bodies from a circular trajectory $\mathrm{B}_{1} D_{1} \mathrm{~A}_{1}$ at point $A 1$ to a parabolic $A_{1} F_{1} B_{1}$, where the grinding body makes a free fall onto the fuel layer in a parabolic way and makes circular movement again at the point of fall.

The quality of milled coal has a large, and sometimes decisive effect on the efficiency of grinding and incineration, as well as, the operation of individual elements of the dust preparation plant, the furnace, and the boiler unit as a whole. Therefore, the amount of supplied milled coal should be given special attention.

Larger dust particles lead to higher productivity of any type of mill and lower specific energy consumption for grinding and transport, lower specific wear of the metal and consumption of lubricant, etc. Of course, coarse-gained dust production is one of the easiest ways to increase grinding efficiency. However, it should be considered that the fineness of the dust has a very strong effect on the combustion process in the furnace, on the stability of ignition, the efficiency of combustion and slugging of heating surfaces [1].

Two different parameter affecting the efficiency are specified:

- The greater the yield of volatiles in the fuel, and the lower its ash content, the coarser the dust can be;

- The greater yield of volatiles in the fuel turns the fuel in combustible gas when heated, the easier it is to ignite this fuel and to maintain stable combustion process. 
The quality of the final dust, ensuring effective combustion is determined primarily by the fineness of its grinding i.e. surface which is usually evaluated by particle size on the basis of sieve analysis of dust samples.

The reliability of dust ignition is directly related to the total residue of dust on a sieve with cell sizes of $90 \mu \mathrm{m}$ (R90), and its complete burnout due to the presence of bigger fractions in dust characterized by the total residue on a sieve with cell sizes of $200 \mu \mathrm{m}$ (R200), which determines heat losses associated with mechanical underburning of fuel [9].

Sieved analysis was performed with an average portion of dust in the amount of $50 \mathrm{~g}$ (Fig. 1). According to the results of sieve analysis $\mathrm{R}_{90}=22.08 \%$, and the magnitude of the total balance amounting to $\mathrm{R}_{200}=4.2 \%$.

The process of ignition and combustion of coal dust with the same fineness of grinding is largely affected by the amount of volatile substances.

A correlation between the fineness of grinding and the amount of volatiles, providing a stable ignition of dust and its complete burnout, was proposed in [10]:

$$
R_{90}=\alpha+\beta V^{v}
$$

where for coals, based on empirical data the values are determined: $\alpha=4 ; \beta=0.7$.

Following Eq. 7, the grinding fineness for Karaganda coals amounts to $R_{90}=23.6$. The experimental study shows $R_{90}=22.08$ which is within $6 \%$ error. This proves a positive statement about correlation of important characteristics of the processed fuel, fineness of grinding and the amount of volatiles in the dry ash-free mass of fuel.

When transferring the experimental data obtained to an existing coal-grinding installation, the coefficient of grinding ability and specific energy consumption for fuel grinding should be considered as the most significant thermotechnical characteristics.

As follows from table 2, the specific energy consumption for fuel grinding varies in the range from $0.11 \mathrm{~kW} \mathrm{~h} / \mathrm{kg}$ up to $0.23 \mathrm{kWh} / \mathrm{kg}$. The values for the specific energy consumption obtained are consistent with the current standards for BDM - 0.15 up to 0.25 $\mathrm{kW} / \mathrm{kg}$ of coal with a fuel milling coefficient of $\mathrm{K}_{1}=1.4$. According to the norms of dustcontrol plants [1], the selection of mills for grinding industrial Karaganda coals is allowed, when $\mathrm{K}_{1} \geq 1.1$.

The results of the sieve analysis confirm the qualitative grinding of the fuel and correspond to the standard values of the fineness of the dust recommended [11].

\section{Conclusion}

The performed experimental study concerns the operational characteristics of BDM for grinding of Karaganda coal products. The results obtained can be used to improve the energy efficiency of large industrial grinding BDM. The following conclusions have been made:

-The relation between productivity, power and specific energy consumption in terms of relative rotational speed of the mill drum is determined;

- The performance of the drum mill reaches its maximum at a relative speed of rotation of the drum 0.71 ensuring a waterfall mode of grinding of fuel related to the highspeed mode of a coal-grinding mill.

-When transferring the experimental data obtained to an existing coal-grinding installation, the coefficient of grinding ability and specific energy consumption for fuel grinding should be considered as the most significant thermotechnical characteristics. 
-The specific energy consumption for fuel grinding varies in the range from $0.11 \mathrm{~kW}$ $\mathrm{h} / \mathrm{kg}$ up to $0.23 \mathrm{kWh} / \mathrm{kg}$ at fuel milling coefficient of $\mathrm{K}_{1}=1.2$.

The development of a methodology for thermodynamic analysis of coal dust preparation, as well as the development of a mathematical model for the operation of a dust preparation plant with BDM-25A with improved technical and economic indicators, is ahead.

\section{References}

1. Levit G T, Dust preparation at thermal power plants. Energoatomizdat, p. 384, 1990

2. Mingalieva A, Zatsarinnaya $\mathrm{Yu}$ and Vachagina E.K, Analysis of the system for the preparation of fuel pulverized CPP, Energy issues, 2005, №1-2, p. 22-31.

3. Prothrombin index 102-47-11. JSC “ArcelorMittalTemirtau” CHP-2, Production and technological instruction manual for the pulverization system with ball mills of the type BDM-320/570, Temirtau 2011, p.19.

4. Abildinova S, Kamarova S, Optimization of electricity costs for dust preparation in Sh25A Sharpen Mills CHP-2 OJSC ArcelorMittalTemirtau, Energy: Management, quality and energy efficiency, Proceedings of the IX International Scientific and Practical Conference, March 11-12, 2019. Blagoveshchensk: AmSU Publishing House, 2019, p.370-376.

5. Sokolova N, Sokolov N, Calculation and design of dust preparation installations for boiler units (Regulatory materials) / Under the general editorship of N. Sokolova, M. Kisselgof. ONTI CKTI, 197, p. 312

6. Savchenko V, Enamelling technology and equipment for enamelling workshops: studies for technical schools / V.I. Savchenko; by ed. L.D. Svirsky. Kharkov: Metallurgizdat, 1961, p.388

7. Pivniak G, Grinding, energy and technology. M: Ore and metals, 2007, p. 238

8. Khakhalev $\mathrm{P}$, Improving the design of the stepped lining and study of the grinding process in a ball-type drum mill, BSTU them, V. G. Shukhov, Belgorod, 2017, p.177

9. Butko A, Educational Complex. Fuel and its use, Minsk: BSU, 2019, p.70

10. Lavrantev A. Y., Tolchinski A. Y., Improving the methods of calculating dust preparation plants, Electrical stations Journal, 2003, Vol. 12, p.p. 45-58

11. Zhukov E, Calculation and design of dust preparation systems: a tutorial E. B. Zhukov; Alt. state tech. un-t them. I. Polzunova, Barnaul: Izd-vo AltGTU, 2015, p. 123 